\title{
Compositional Effects of Gasoline Fuels on Combustion, Performance and Emissions in Engine
}

\author{
Ahfaz Ahmed, Muhammad Waqas, Nimal Naser, Eshan Singh, William Roberts, Sukho Chung, \\ and Mani Sarathy \\ King Abdullah Univ of Science \& Tech
}

\begin{abstract}
Commercial gasoline fuels are complex mixtures of numerous hydrocarbons. Their composition differs significantly owing to several factors, source of crude oil being one of them. Because of such inconsistency in composition, there are multiple gasoline fuel compositions with similar octane ratings. It is of interest to comparatively study such fuels with similar octane ratings and different composition, and thus dissimilar physical and chemical properties. Such an investigation is required to interpret differences in combustion behavior of gasoline fuels that show similar knock characteristics in a cooperative fuel research (CFR) engine, but may behave differently in direct injection spark ignition (DISI) engines or any other engine combustion modes. Two FACE (Fuels for Advanced Combustion Engines) gasolines, FACE F and FACE G with similar Research and Motor Octane Numbers but dissimilar physical properties were studied in a DISI engine under two sets of experimental conditions; the first set involved early fuel injection to allow sufficient time for fuel-air mixing hence permitting operation similar to homogenous DISI engines, while the second set consists of advance of spark timings to attain MBT (maximum brake torque) settings. These experimental conditions are repeated across different load points to observe the effect of increasing temperature and pressure on combustion and emission parameters. The differences in various engine-out parameters are discussed and interpreted in terms of physical and thermodynamic properties of the fuels.
\end{abstract}

CITATION: Ahmed, A., Waqas, M., Naser, N., Singh, E. et al., "Compositional Effects of Gasoline Fuels on Combustion, Performance and Emissions in Engine," SAE Int. J. Fuels Lubr. 9(3):2016, doi:10.4271/2016-01-2166.

\section{INTRODUCTION}

With the evolving trend of engine downsizing and turbocharging to increase efficiency, internal combustion (IC) engine operation practices have advanced significantly from historically prescribed ASTM standards (D2699 [1]], D2700 [2] ). The evolution of engine technology oversaw extensive modifications in engine geometry and combustion processes. This development also led gasoline fuels to become increasingly complex in composition and properties to meet diverse performance requirements. Such elaborate compositions allow multiple degrees of freedom to achieve desired fuel properties. Consequently, many fuel formulations with diverse compositional details can maintain vital performance targets, such as Research Octane Number (RON) and Motor Octane Number (MON), within a narrow range as seen in FACE gasolines [3] . This variability in composition could lead to differences in fuel's physical and thermodynamic properties, which might have significant effects on various processes in an IC engine, hence a systematic investigation is necessary. Such a study must be conducted in a combustion mode where the fuel's physical properties exhibit evident effects on mixture formation and combustion. A number of investigations indicate that DISI engine is more sensitive to fuel properties $[\underline{4}, \underline{5}, \underline{6}, \underline{7}]$. Furthermore octane requirement studies of direct injection spark ignition (DISI) [ $\underline{8}$ ] engines indicate that fuels with high RON and high sensitivity ( $\mathrm{S}=\mathrm{RON}-\mathrm{MON}$ ) are more suited. FACE F and $\mathrm{G}$ gasolines []ㅡ differ significantly in composition and have high RON and high sensitivities, thus making DISI mode suitable for this study.

DISI engines offer a flexibility over conventional port fuel injection (PFI) engines [9] , enabling higher power to weight ratio by allowing higher compression of air before fuel injection, lean throttle-less operation at low loads [7] and advantages of charge cooling due to spray evaporation. The latter effect suppresses pre-combustion temperatures effectively mitigating thermal NOx production during combustion. However, the available time for fuel to mix with air can be considerably less in DISI mode as compared to PFI operation, which leads to a greater dependence of combustion processes on fuel properties such as density, volatility, diffusion, and viscosity. $[\underline{4}, \underline{10}]$. 
Differences in these factors often lead fuels with similar research and motor octane numbers to demonstrate distinguishable effects on combustion, emission and performance of a DISI engine $[\underline{5}, \underline{11}]$.

Several studies have investigated the effects of fuel composition on various aspects in a DISI engine. Davy et al. [7] conducted an experimental study to explore the effects of fuel composition on mixture formation in a DISI engine and concluded that mean droplet diameter and mixture formation are strong functions of fuel composition, and thereby affects combustion and emissions critically. Carlisle et al. [12] examined the effects of fuel composition and $\mathrm{T}_{90}$ on deposit formation on injectors. The role of aromatic contents was found to be significant in promoting injector deposits while the effects of olefins and $\mathrm{T}_{90}$ was inconsequential. Zigan et al. [13] experimentally investigated the effects of fuel properties and ambient conditions on spray breakup and evaporation. At higher temperatures, the droplet evaporation rate was governed primarily by composition. Also the heavier fractions in multicomponent fuels were found to increase the spray liquid lengths.

In the present investigation two FACE gasolines []ㅡ, FACE F and $\mathrm{G}$ with similar anti-knock index (AKI) and different physical and compositional aspects (Table 1) are studied in a single cylinder DISI research engine across a range of experimental conditions. Figure 1 represents the advanced distillation curve (ADC) measurement for FACE F and G, the advantages of ADC over conventional ASTM D-86 are:

- The temperature is measured in kettle which is a thermodynamic point and hence could be modelled using equation of states.

- The experiment doesn't allow volatile fraction to escape the distillation column and minimizes reflux by design.

- The distillate is sampled in level stabilized columns allowing precise measurement.

This study incorporates engine experiments, GT-power simulations and enhanced application of fuel properties to understand how compositional differences of FACE F and G affect various in-cylinder processes and emissions.

Table 1. Properties of gasoline FACE F and FACE G

\begin{tabular}{|l|l|l|}
\hline Properties & FACE F & FACE G \\
\hline RON & 94.4 & 96.5 \\
\hline MON & 88.8 & 85.4 \\
\hline AKI (RON+MON)/2 & 91.6 & 91 \\
\hline S (RON-MON) & 5.6 & 11.1 \\
\hline H/C ratio & 2.1 & 1.83 \\
\hline Density @ 288 K (Kg/m $\left.{ }^{3}\right)$ & 707 & 733 \\
\hline LHV(KJ/Kg) & 44361 & 43268 \\
\hline N-paraffins (mol \%) & 4.9 & 7.8 \\
\hline Iso-paraffins (mol \%) & 61 & 38.2 \\
\hline Cyclo paraffins (mol \%) & 15.4 & 14 \\
\hline Aromatics (mol \%) & 8.8 & 31.7 \\
\hline Olefins (mol \%) & 9.7 & 8 \\
\hline Stoichiometry & 14.67 & 15.10 \\
\hline
\end{tabular}

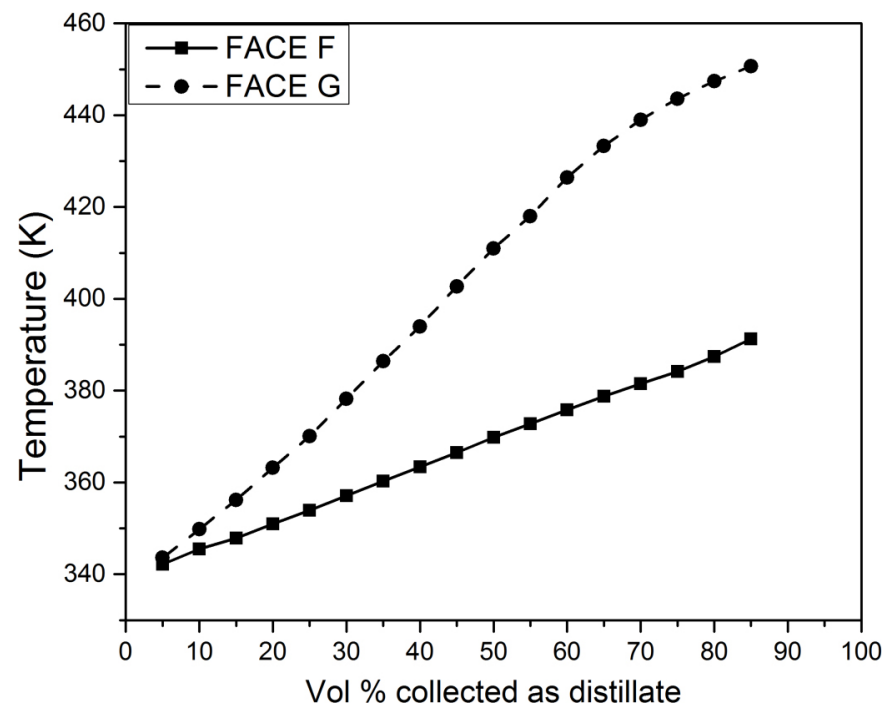

Figure 1. Advanced distillation curve profile for FACE F and FACE G from Burger et al.[14]

\section{EXPERIMENT}

\subsection{Experimental Setup}

Engine experiments were conducted in a single cylinder DISI engine (AVL 5405) at 1500 RPM and at different load conditions, i.e., 40, 60, 80 and $100 \%$. The exhaust gasses were analyzed for concentration of regulated emissions of $\mathrm{CO}, \mathrm{HC}, \mathrm{CO}_{2}$ and $\mathrm{NO}_{x}$ with an exhaust gas analyzer (AVL AMA i60) and smoke meter (AVL 415s) to obtain filter smoke number (FSN). Fuel was injected with a centrally mounted piezoelectric gasoline direct injection (GDI) injector at a pressure of 135 bar. The engine pressure traces were acquired with a resolution of $1 \mathrm{CAD}$ and averaged for 330 cycles.

Details of the engine and fuel injection system are provided in Table 2. The engine was operated at two sets of operating conditions; the first set was carried out with early fuel injection timings with spark at TDC (Table 3), while the second set involved early fuel injection with advanced spark timings (Table 4). The first set was intended to simulate homogenous DISI conditions across different loads, however owing to the differences in density and volatility of fuels, the degree of premixing at spark was different. In the second set, spark timing was advanced to attain maximum brake torque (MBT). Along with other factors, MBT depends on fuel burn rates, which is different for both the fuels, and results in difference in cylinder conditions. Throughout the experiments, the engine was operated at $\lambda$ $=1$. The coolant and oil temperature was maintained at $80 \pm 2{ }^{\circ} \mathrm{C}$ and intake air was conditioned to maintain $1 \mathrm{bar}, 25^{\circ} \mathrm{C}$ and $6 \mathrm{~g} / \mathrm{Kg}$ of humidity during the experiments. 
Table 2. Engine and fuel injection system specifications

\begin{tabular}{|l|r|}
\hline Engine Type & $\begin{array}{l}\text { Single cylinder NA engine operated in DISI } \\
\text { mode }\end{array}$ \\
\hline Cylinder bore & $82.00 \mathrm{~mm}$ \\
\hline Stroke & $86.00 \mathrm{~mm}$ \\
\hline Swept volume & $454.00 \mathrm{~cm}^{3}$ \\
\hline Injection Pressure & $135 \mathrm{Bar}$ \\
\hline Compression ratio & 11.5 \\
\hline Lambda $(\lambda)$ & 1 \\
\hline Engine RPM & 1500 \\
\hline Fuel injector & $\mathrm{GDI}$ \\
\hline Fuel injection pressure & $135 \mathrm{bar}$ \\
\hline Coolant temperature & $80^{\circ} \mathrm{C}$ \\
\hline Lubricant temperature & $80^{\circ} \mathrm{C}$ \\
\hline IVO: $-360^{\circ} \mathrm{CA}$ & IVC: $-140^{\circ} \mathrm{CA}$ \\
\hline EVO: $140^{\circ} \mathrm{CA}$ & $\mathrm{EVC}: 360^{\circ} \mathrm{CA}$ \\
\hline
\end{tabular}

Table 3. Experimental details of first set of experiments at various load conditions

\begin{tabular}{|l|l|l|l|l|l|l|l|}
\hline \multicolumn{2}{|l|}{} & \multicolumn{3}{c|}{ FACE F } & \multicolumn{3}{c|}{ FACE G } \\
\hline RPM & $\begin{array}{l}\text { Load } \\
\%\end{array}$ & IMEP & $\begin{array}{l}\text { Injection } \\
\text { Time }\end{array}$ & $\begin{array}{l}\text { Ignition } \\
\text { Time }\end{array}$ & $\begin{array}{l}\text { Injection } \\
\text { Time }\end{array}$ & $\begin{array}{l}\text { Ignition } \\
\text { Time }\end{array}$ & IMEP \\
\hline 1500 & 40 & 8.6 & -300 & 0 & -300 & 0 & 8.5 \\
\hline 1500 & 60 & 9 & -300 & 0 & -300 & 0 & 8.9 \\
\hline 1500 & 80 & 9.1 & -300 & 0 & -300 & 0 & 9 \\
\hline 1500 & 100 & 9.1 & -300 & 0 & -300 & 0 & 9 \\
\hline
\end{tabular}

Table 4. Experimental details of second set of experiments at various load conditions

\begin{tabular}{|c|c|c|c|c|c|c|c|}
\hline & & \multicolumn{3}{|c|}{ FACE F } & \multicolumn{3}{c|}{ FACE G } \\
\hline RPM & $\begin{array}{c}\text { Load } \\
\%\end{array}$ & IMEP & $\begin{array}{c}\text { Injection } \\
\text { Time }\end{array}$ & $\begin{array}{l}\text { Ignition } \\
\text { Time }\end{array}$ & $\begin{array}{c}\text { Injection } \\
\text { Time }\end{array}$ & $\begin{array}{c}\text { Ignition } \\
\text { Time }\end{array}$ & IMEP \\
\hline 1500 & 40 & 9.8 & -300 & -16 & -300 & -12 & 9.7 \\
\hline 1500 & 60 & 10.2 & -300 & -12 & -300 & -10 & 10 \\
\hline 1500 & 80 & 10.3 & -300 & -12 & -300 & -10 & 10.2 \\
\hline 1500 & 100 & 10.3 & -300 & -12 & -300 & -10 & 10.2 \\
\hline
\end{tabular}

The compositions of FACE F and G gasolines [15] were obtained with detailed hydrocarbon analysis (DHA) in compliance with ASTM standards D6733 and D6730 [투]. Detailed thermodynamic data were also compiled for all the species of FACE F and G to generate NASA [17] polynomials to predict thermodynamic properties of these fuels.

\section{ENGINE MODELLING WITH GT-POWER}

An engine model (AVL 5405) was created using GT power software, version 7.5 .0 build 4 [르]. A closed cycle method (from IVC to EVO) was employed with precise details of engine operation and geometry as mentioned in Table 2. GT power engine simulations were performed using the reverse-run methodology to retrace experimental pressure data with a modeled pressure trace. The reverse run method employs a two-zone model for analysis of the combustion chamber, i.e., burnt and unburned zone, the burnt zone consumes fuel from the unburned zone depending on the burn rate. The burn rate calculations are performed at each time step, as a charge transfer rate from unburned to burnt zone, eventually defining several parameters including heat release rate, combustion phasing and predicted pressure profile. During the simulation, it was assumed that initially all the constituents in the cylinder are in the unburned zone including the residual gases from the previous cycle and EGR (none in this case). The two zones are separated by infinitely thin flame front and no heat exchange is allowed between the two zones. The cylinder pressure is considered spatially uniform during the calculations and all the gasses behave as ideal.

During the course of simulations, the engine model requires various input parameters including experimental pressure profile, emission concentrations, injected fuel quantity and a convective heat transfer coefficient between the in-cylinder media and the walls. Here, heat loss is modelled as forced convection with the heat transfer model proposed by Woshini [19]. These parameters are utilized within the model to predict a pressure trace, which is eventually matched with experimental pressure data by adjusting the convective heat transfer coefficient. The convective heat transfer coefficient $(h)$ is assigned a discretized range of values using the design of experiments (DOE) tool during the simulation. The DOE functionality allows discretized variation of $h$ within this pre-defined range and the value of $h$ enabling closest match of experimental and modeled pressure data is taken as an optimum value for the respective set of experiments. The engine model can then be utilized to predict several in-cylinder crank resolved parameters by means of a tuned modeled pressure profile. This exercise was repeated for both set of experiments to capture actual heat loss characteristics of the engine at its respective experimental state. Furthermore, in cases where MBT conditions were attained by spark advance, mild knock was observed experimentally and hence a knock analysis (KnockAnalysis) object was added to the GT power engine model to account for knock in the end gas zone by detecting and characterizing pressure oscillations.

Since this study emphasizes the effect of physical properties on engine combustion, it is imperative to use surrogate fuels which accurately represent physical, thermodynamic and chemical kinetic properties of FACE F and G. A recent study by Sarathy et al. [15] investigated ignition chemistry of FACE F and G, together with multi-component surrogate fuels for each fuel and detailed chemical kinetic modeling simulations. The multi-component surrogates matched multiple physical properties and satisfactorily predict ignition delay over wide ranges of pressure, temperature and equivalence ratio regimes. In this study, the multi-component LLNL surrogates have been utilized for engine modeling and analysis due to 
their relative simpler composition as compared to KAUST multicomponent surrogates. The detailed combustion chemistry model developed in Sarathy et al. [15] was also used.

The fuel library within the standard GT-power software distribution does not comprise of all the species needed to describe LLNL surrogate fuels [15], and hence it was modified to accommodate the following species: cyclopentane, 1-hexene and

1,2,4-trimethylbenzene. The properties for the fluid and vapor objects for GT power were taken from NIST webbook [20]. The composition and properties of surrogates are shown in Tables 5 and $\underline{6}$, respectively. Distillation curves for FACE F and G along with respective surrogates are shown in Figs. 2 and $\underline{3}$. The distillation profiles for surrogates were calculated with Refprop [21] using methodology described by Ahmed et al. [22]].

Table 5. Composition of surrogate fuels in mole percentages for FACE F and FACE G reported in Sarathy et al.[15]

\begin{tabular}{|l|c|c|}
\hline Palette compound & FGF-LLNL & FGG-LLNL \\
\hline n-Butane & 0 & 0 \\
\hline 2-Methyl butane & 0 & 0 \\
\hline 2-Methyl hexane & 0 & 0 \\
\hline Cyclopentane & 14 & 14 \\
\hline 1,2,4-Trimethylbenzene & 0 & 31 \\
\hline 1-Hexene & 14 & 9 \\
\hline n-Heptane & 7 & 8 \\
\hline 2,2,4-Trimethylpentane & 53 & 38 \\
\hline Toluene & 12 & 0 \\
\hline
\end{tabular}

Table 6. Properties of FACE F, FACE G and surrogates reported in Sarathy et al. [15]

\begin{tabular}{|l|c|c|c|c|}
\hline Properties & FACE F & FGF-LLNL & FACE G & FGG-LLNL \\
\hline RON & 94.4 & 93.8 & 96.8 & 96.4 \\
\hline MON & 88.8 & 89.5 & 85.8 & 85.5 \\
\hline Density & 707 & 712.37 & 760 & 751 \\
\hline H/C & 2.13 & 2.06 & 1.84 & 1.87 \\
\hline Mwt. & 94.8 & 100.18 & 98.973 & 106 \\
\hline
\end{tabular}

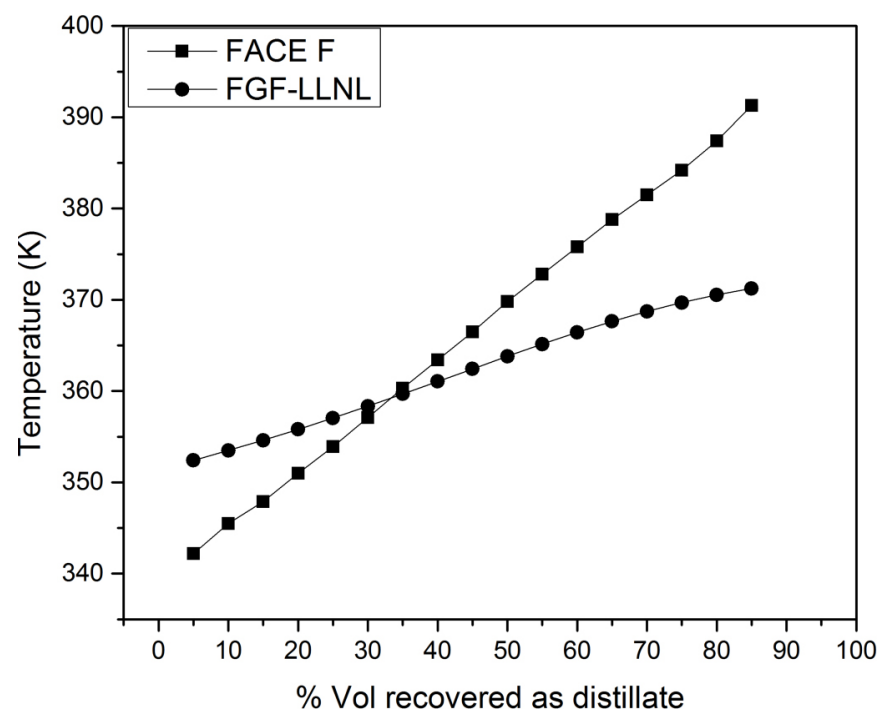

Figure 2. Advanced ditillation curve for FACE F and its surrogate FGF-LLNL

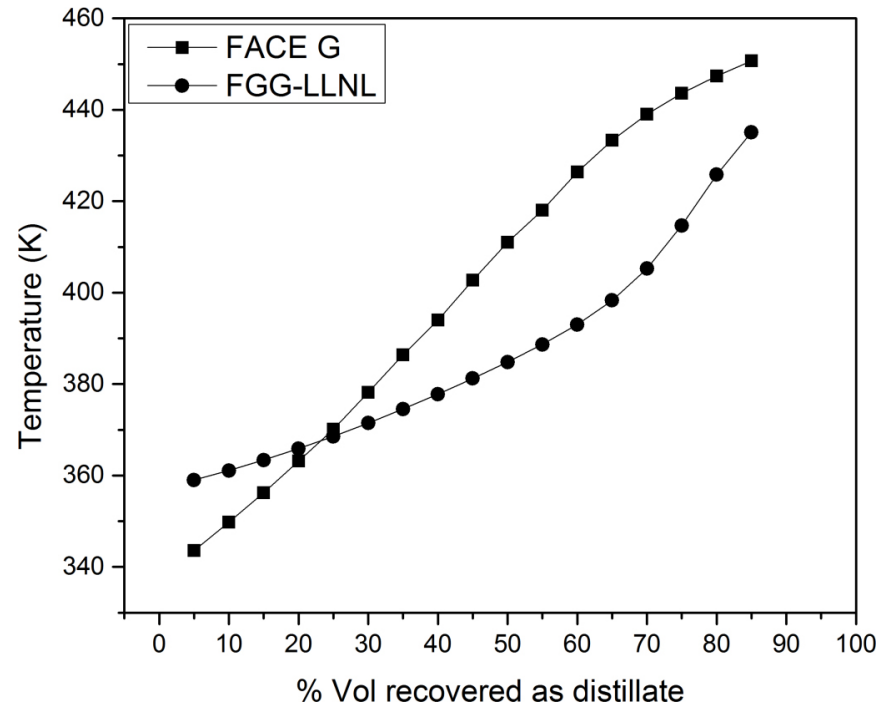

Figure 3. Advanced distillation curves for FACE G and its surrogate FGG-LLNL

\section{RESULTS AND DISCUSSIONS}

Results from GT power simulations are presented in the following section. As discussed, the engine experiments and simulations were conducted for 40, 60, 80 and $100 \%$ load points at 1500 RPM for all cases; however the results section discusses selected experiments and simulations, i.e., one part load condition (40\%) and full load condition from each case. These two experimental conditions are selected for discussing the effect of fuel properties and composition.

Different cases of engine experiments are discussed independently to facilitate comparison between fuels and their corresponding impact on combustion and emission parameters. Also each case is described in a distinctive manner and different parameters are discussed to highlight the differences between fuels in various experimental settings.

\subsection{Case 1: Early Injections with Spark Timing at TDC}

The first set of experimental results discusses cases where FACE F and $\mathrm{G}$ are injected early as shown in Table 3 , allowing sufficient time for fuel-air mixing before sparking at TDC. Figure 4 shows the pressure trace comparison of FACE F and G at full load. This case details the comparison between two fuels in settings where the charge is assumed to be predominantly premixed before combustion, however, the degree of premixedness may be different. In such a setting, physical properties tend to show minimal effect on mixture formation, however, the composition would impact emission concentrations and other in-cylinder processes. In this case, FACE F and G are compared on three quantities, namely heat release rate, temperature of unburned and burnt zones and emission concentrations. 


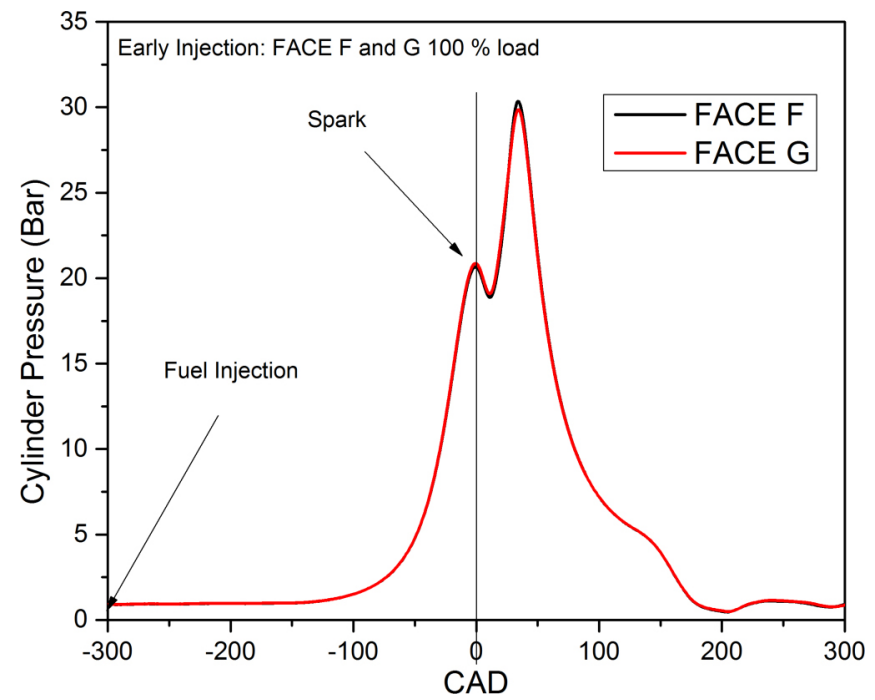

Figure 4. Pressure trace from engine showing pressure profiles for FACE F and FACE G for case of early injection and spark at TDC

Heat release rates (HRR) were calculated as fraction of total fuel energy (normalized) to account for cumulative effect of mass and energy of fuel injected for part and full load conditions, as shown in Figure 5. HRR comparison for FACE F and G highlights identical combustion phasing and burning characteristics under similar experimental conditions. Figure 6 shows temperature profiles of unburned fuel air mixtures, wherein FACE G indicates higher temperature upon compression (by flame front and piston) due to lower heat capacity and higher heat capacity ratio (Fig. 7). Such thermodynamic attributes of a fuel makes it more prone to uncontrolled auto-ignition (knock) in the end gas zone as compared to a gasoline of equivalent octane index and higher heat capacity. Burnt zone temperatures are calculated and showed in Fig. 8 for both the fuels. FACE G shows higher temperatures in the burnt gas regime partly due to higher pre-combustion temperatures and also due to lower stoichiometric air/fuel ratio, which leads to an addition of higher fuel quantity to the engine for the same equivalence ratio.

Due to cascading effects of thermodynamic properties and composition on temperature profiles in unburned and burnt zones, FACE G shows a higher thermal NOx concentration (i. $\underline{\text { Fig. 9) }}$ in the exhaust due to higher peak temperatures. FACE G also shows higher filter smoke numbers (FSN) across load points (ig. 9) probably due to higher aromatic content, which tends to act as precursors to soot formation. HC emissions could be related to unburned fuel mass trapped in the combustion chamber crevices. Another possible reason for $\mathrm{HC}$ emissions is attributed to absorption of fuel vapor on the cylinder wall due to early injection which is later desorbed during the exhaust stroke due to reduction of pressure in the combustion chamber [10]. In the present case, the latter reason seems to be a major cause of $\mathrm{HC}$ emissions since FACE G is less volatile than FACE F, which would lead to enhanced absorption on the cylinder liner.

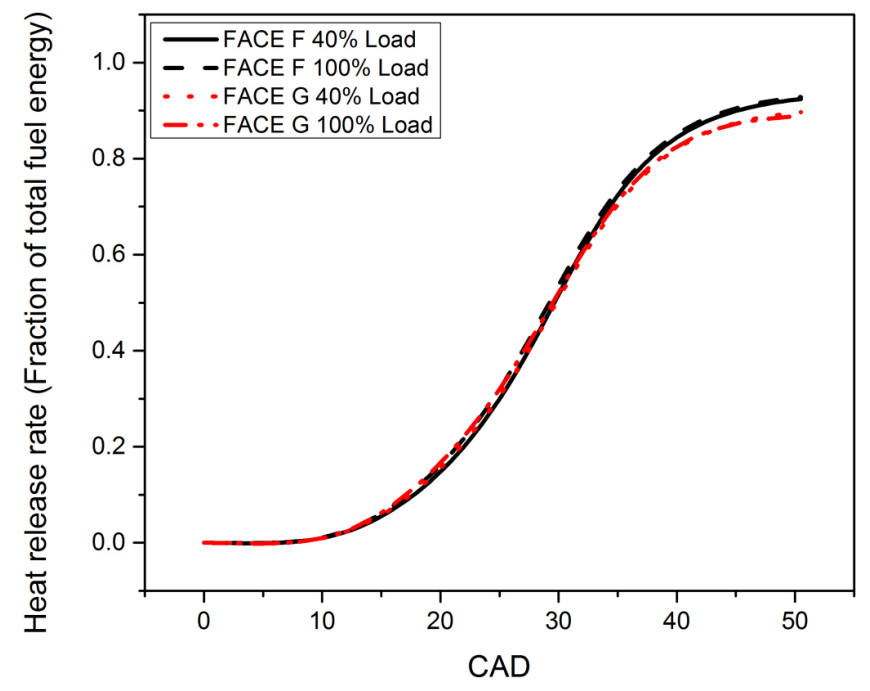

Figure 5. Heat release rate (normalized) as a fraction of total fuel energy vs CAD for FACE $\mathrm{F}$ and $\mathrm{G}$ for case with early injection

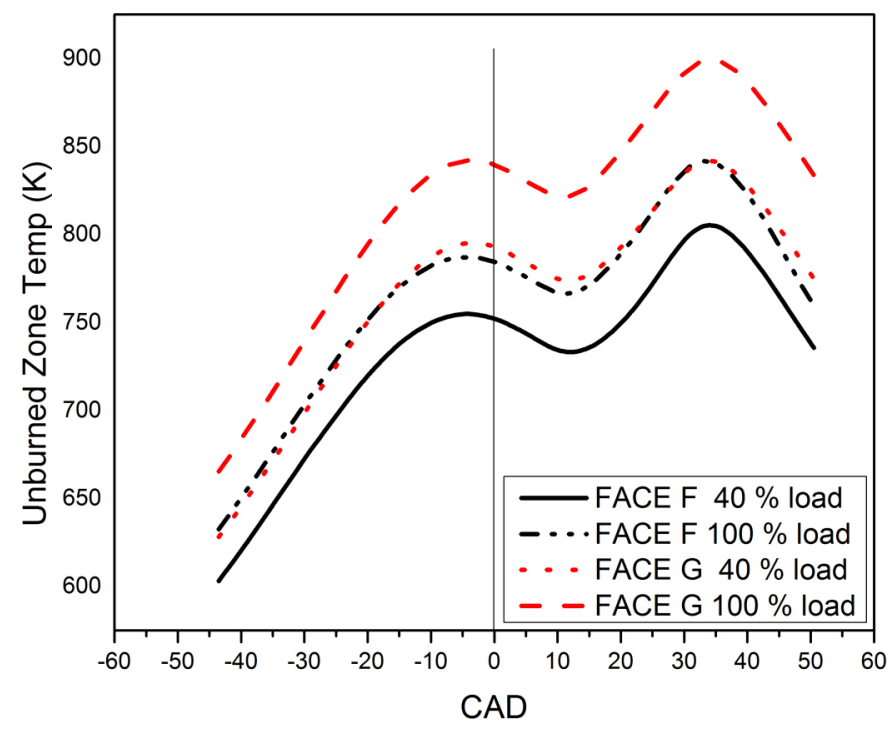

Figure 6. Temperature variation of end-gas (unburned fuel-air mixture) for FACE $F$ and $G$ at part load and full load

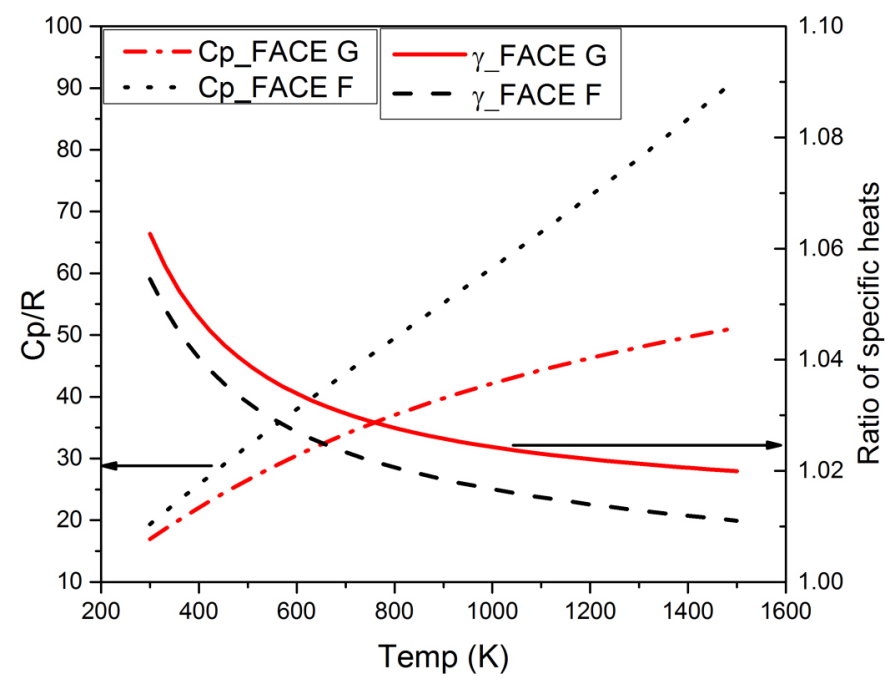

Figure 7 . Heat capacity $(\mathrm{Cp} / \mathrm{R})$ and ratio of heat capacity $(\gamma)$ comparison of gasoline FACE F and $\mathrm{G}$ 


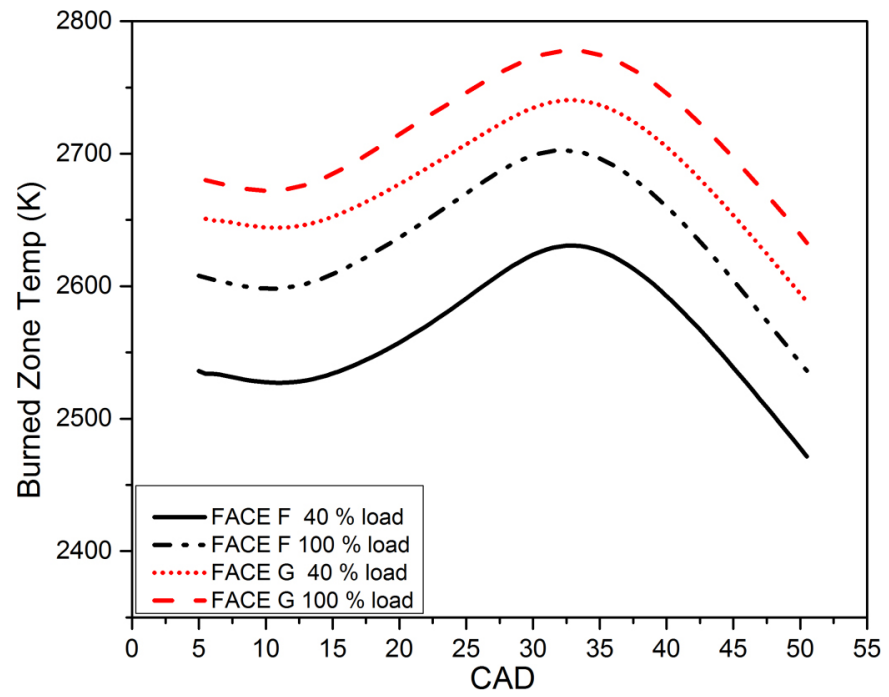

Figure 8. Temperature variation of burned gas for FACE F and G at part load and full load

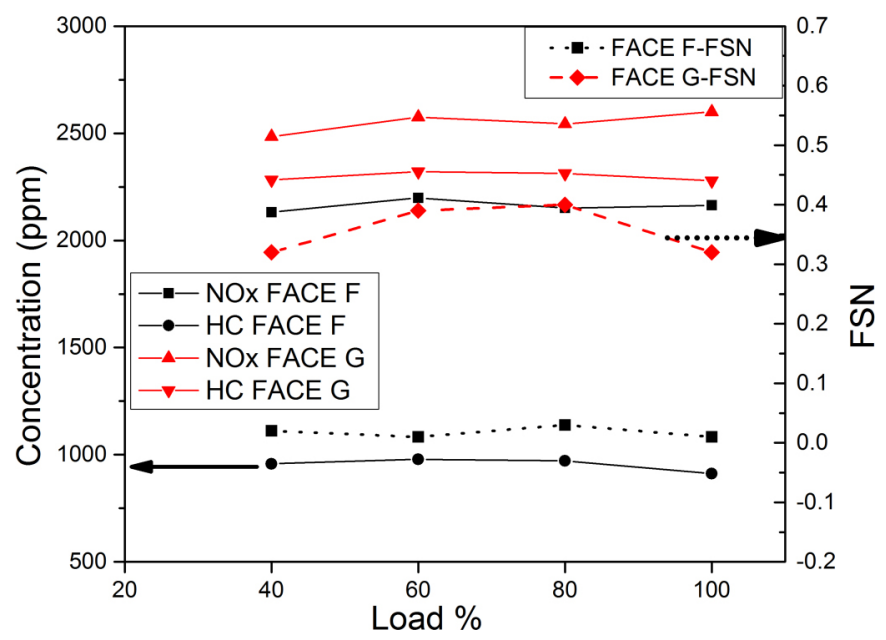

Figure 9. Pollutant formation comparison: NOx, HC and FSN for FACE F and $\mathrm{G}$ at part and full load

Hence, the differences arising between two fuels have been detailed in predominantly premixed combustion setting on the basis of physical and thermodynamic properties of the fuels.

\subsection{Case 2: Spark advance limited by Maximum Brake Torque}

The second set of engine experiments were conducted at MBT conditions attained by advancing spark timing for FACE $F$ and $G$ gasolines. The spark timing is critical to maximize engine torque as early spark reduces torque by increasing piston work on gasses, while delayed spark minimizes the attained peak cylinder pressure thereby reducing torque attained. In order to realize MBT, the spark timing should be adjusted to ensure maximum work transfer from the expanding combustion gases to the piston, which also facilitates minimum brake specific fuel consumption (BSFC). The magnitude of the spark advance required to reach MBT increases as engine rpm increases.
However, while spark advance enables maximum power output, it also increases in-cylinder burnt and unburned gas temperatures, resulting into higher probability of auto-ignition in the unburned zone and higher NOx formation in the burnt zone. Figure 10 shows an experimental pressure trace from such an experiment for FACE F and $\mathrm{G}$ and Table 4 presents the experimental conditions for this case.

As detailed in Table 4, higher spark advance was needed for FACE F at part and full load conditions as compared to FACE G to reach MBT. As discussed earlier, higher spark advance indicates lower burn rates or higher burn duration at respective experimental condition. In Fig. 11, FACE F confirms lower burn rate as compared to FACE G across loads which could be attributed to relatively higher IMEP (Fig. $\underline{10}$ ) and lower burn temperatures (Fig. 12).

The comparison in Fig. 11 also highlights the effect of pressure and temperature on burn rates, despite of predominantly lighter composition, FACE F is showing slower burn rate due to in-cylinder ambient conditions.

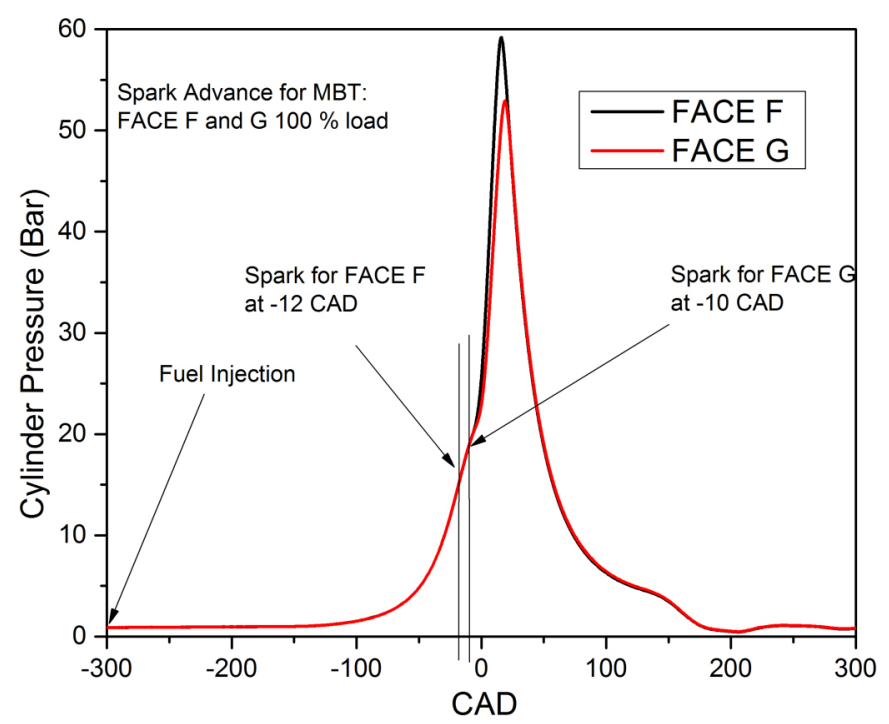

Figure 10. Pressure trace from engine showing pressure profiles for maximum brake torque case for FACE F and FACE G

Spark advance leading to MBT also yields higher temperatures in end gas zone corresponding to thermodynamics of fuel-air mixture thus promoting prospects of auto-ignition. Such an event is presented for FACE F and $\mathrm{G}$ at $100 \%$ load in Fig. 13, pressure fluctuations $(k p)$ confirm the existence of auto ignition in the end gas zone. FACE G has higher RON and sensitivity than FACE F and thus is expected to show higher octane index $(O I=R O N-K S)$ under severe combustion environments. This effect of higher octane index is evident in Fig. 13 wherein FACE G shows similar magnitude of pressure fluctuations despite of higher end gas temperatures, thus confirming FACE G's higher resistance to knock. 


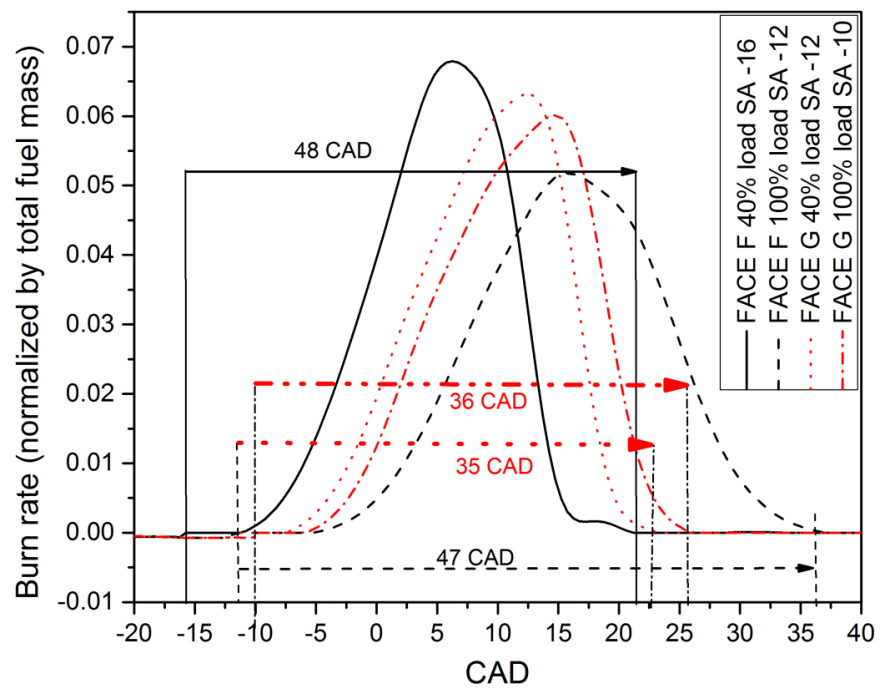

Figure 11. Burn rates (normalized by total fuel mass) are shown for different cases for FACE F and G for MBT events.

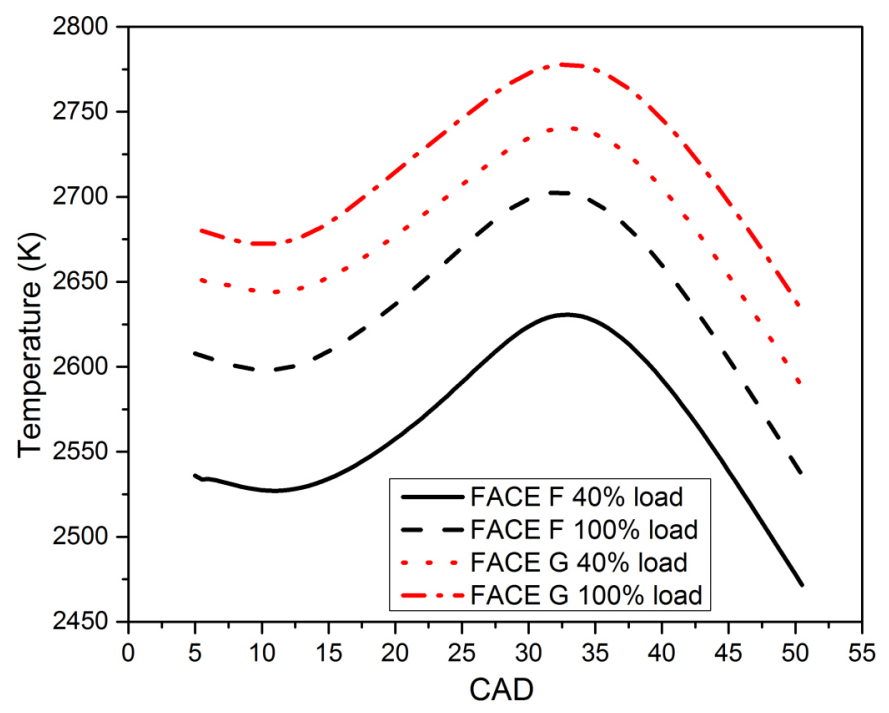

Figure 12. Burned zone temperatures for FACE F and FACE G at various load points for MBT condition

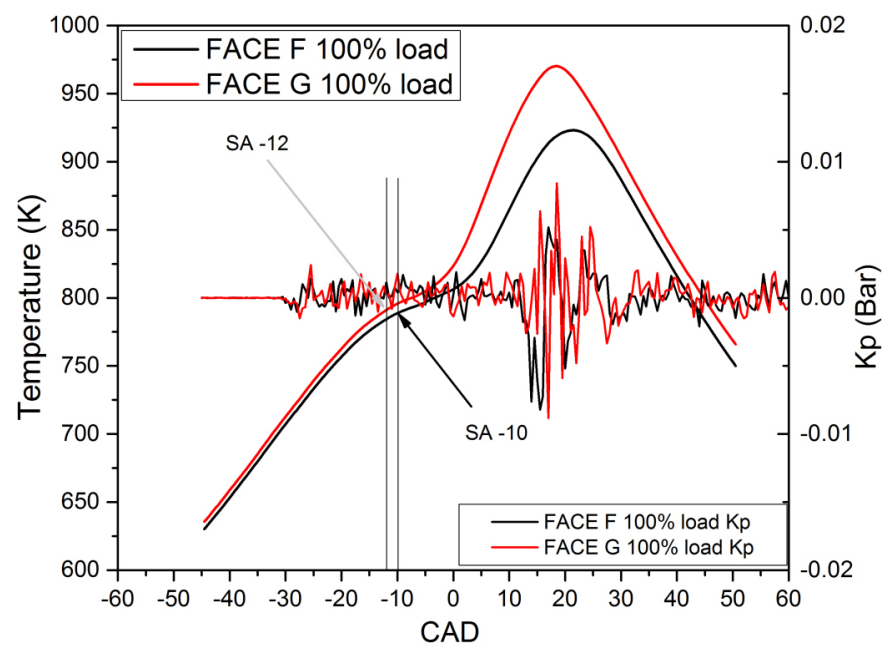

Figure 13. Temperature profiles of unburned charge for FACE F and G and their knock intensities for MBT conditions
Due to higher peak temperatures consistently across the load points, FACE $\mathrm{F}$ and $\mathrm{G}$ show a jump in NOx emission concentrations as compared to Case 1 as shown in Fig. 14. Due to such higher NOx concentrations at MBT, the spark timing is set slightly lower or higher than required for MBT. The soot concentration indicated by FSN shows a sharp increase for FACE G upon spark advance, however, FACE F does not show any significant variation. Such behavior is observed earlier by Maricq et al. [23] and could be explained by higher burn rates and higher spark advance and heavier composition of FACE G. These factors cumulatively allow less time for fuel evaporation and hence contribute to higher soot concentrations by allowing fuel rich pockets within the combustion chamber. However, such factors seem to be less significant for FACE $\mathrm{F}$ due to slower burn rates under existing experimental conditions and predominantly lighter composition.

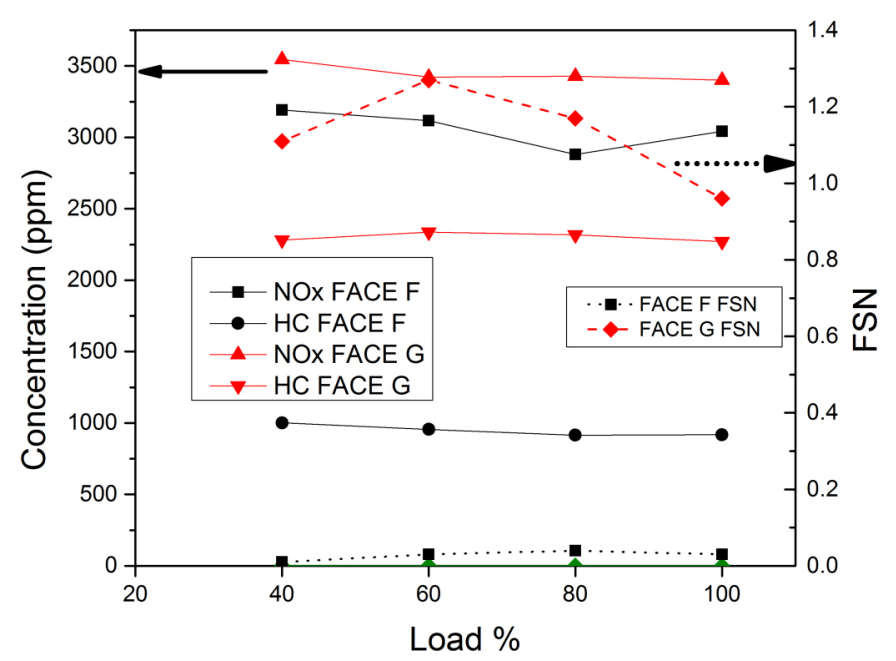

Figure 14. Emissions concentrations for the case of maximum brake torque: $\mathrm{HC}, \mathrm{NOx}$ and FSN

\section{CONCLUSIONS}

Two FACE gasolines, FACE F and G, with same AKI and different sensitivity were studied in a single cylinder DISI engine (AVL 5405) at two sets of experimental conditions to study the effect of fuels' physical properties and chemical composition on combustion characteristics, in cylinder pressure, temperature and emissions at various load points; (1) early fuel injection with spark at TDC and (2) early fuel injection with spark timing advance to attain MBT.

Crank angle resolved pressure traces were acquired and averaged for 330 cycles with resolution of $1^{\circ}$. Exhaust gases were analyzed for measuring concentration of regulated pollutants. Since the concentration of soot produced is minimal, the smoke meter (AVL 415 s) was used to indicate the sooting propensities of FACE F and G at several experimental conditions.

A closed cycle model for the engine (AVL 5405) is created with GT power using precise engine geometry, acquired pressure traces and emission concentrations are input parameters for the model. Modeled pressure traces were predicted using reverse run methodology to calculate various in-cylinder parameters including heat release rates, 
burnt and unburned zone temperatures and fuel burn rates. Detailed calculations were performed for various cases of engine experiments and following conclusions were drawn based on fuel composition and subsequent bulk properties. Based on the experimental and modelling analysis some important conclusions are made which are applicable to fuels FACE F and G.

Conclusions from this study:

1. Fuel with higher aromatics content tend to produce higher soot and higher $\mathrm{HC}$ emissions at all conditions.

2. Fuel with lower heat capacity and higher heat capacity ratio would demonstrate higher unburned zone temperatures and is more prone to knock when compared to a fuel with same octane rating.

3. Fuel with lower heat capacities and lower stoichiometric air requirement will show higher NOx emissions. This is in part due to higher pre-combustion temperatures and partly due to higher fuel quantity resulting into higher peak combustion temperature.

4. Fuel burn rate is not an independent function of fuel composition, it also varies depending on thermodynamic properties of fuel which affects in-cylinder pressure and temperature.

5. Fuel with lower volatility demonstrate a sudden jump in soot concentrations at MBT condition due to lesser time available for fuel vaporization.

\section{REFERENCES}

1. ASTM International, "Standard Test Method for Research Octane Number of Spark-Ignition Engine Fuel," ASTM Standard D2699-13b, 2013.

2. ASTM International, "Standard Test Method for Motor Octane Number of Spark-Ignition Engine Fuel," ASTM Standard D2700-14, 2014.

3. Canella, W., Foster, M., Gunter, G., Leppard, W., "FACE Gasolines and Blends with Ethanol: Detailed Characterization of Physical and Chemical Properties," Coordinating Research Council Report No. AVFL-24, 2014.

4. Davies, T., Cracknell, R., Lovett, G., Cruff, L. et al., "Fuel Effects in a Boosted DISI Engine," SAE Technical Paper 2011-01-1985, 2011, doi: $\underline{10.4271 / 2011-01-1985}$

5. Han, Z., Yi, J., and Trigui, N., "Stratified Mixture Formation and Piston Surface Wetting in a DISI Engine," SAE Technical Paper 2002-01-2655, 2002, doi:10.4271/2002-01-2655.

6. Hochgreb, S., "Fuel Distribution and Combustion Characteristics in a Direct-Injection, Spark-Ignited (DISI) Engine Under Stratified Operation," SAE Technical Paper 2001-01-3645, 2001, doi: $10.4271 / 2001-01-3645$

7. Davy, M., Williams, P., and Anderson, R., "Effects of Fuel Composition on Mixture Formation in a Firing Direct-Injection Spark-Ignition (DISI) Engine: An Experimental Study using Mie-Scattering and Planar LaserInduced Fluorescence (PLIF) Techniques," SAE Technical Paper 2000 01-1904, 2000, doi:10.4271/2000-01-1904.

8. Kalghatgi, G., Nakata, K., and Mogi, K., "Octane Appetite Studies in Direct Injection Spark Ignition (DISI) Engines," SAE Technical Paper 2005-01-0244, 2005, doi:10.4271/2005-01-0244.
9. Alkidas, A. and El Tahry, S., "Contributors to the Fuel Economy Advantage of DISI Engines Over PFI Engines," SAE Technical Paper 2003-01-3101, 2003, doi:10.4271/2003-01-3101

10. Machado, G., Barros, J., Braga, S., and Braga, C., "The Impact of Fuel Composition on SI Engine Calibration and Performance," SAE Technical Paper 2014-36-0161, 2014, doi: 10.4271/2014-36-0161

11. Alkidas, A. C. "Combustion advancements in gasoline engines," Energy Conversion and Management 48:2751-61, 2007 doi:10.1016/j. enconman.2007.07.027

12. Carlisle, H., Frew, R., Mills, J., Aradi, A. et al., "The Effect of Fuel Composition and Additive Content on Injector Deposits and Performance of an Air-Assisted Direct Injection Spark Ignition (DISI) Research Engine," SAE Technical Paper 2001-01-2030, 2001, doi: 10.4271/2001-01-2030.

13. Zigan, L., Schmitz, I., Flügel, A., Knorsch, T., Wensing, M., Leipertz, A., "Effect of fuel properties on spray breakup and evaporation studied for a multihole direct injection spark ignition injector," Energy \& Fuels 24 (8) 4341-4350, 2010: doi: 10.1021/ef1003914

14. Burger, J.L., Schneider, N., Bruno, T.J., "Application of the Advanced Distillation Curve Method to Fuels for Advanced Combustion Engine Gasolines," Energy \& Fuels 201529 (7), 4227-4235 doi: 10.1021/acs. energyfuels.5b00749

15. Sarathy, S.M., Kukkadapu, G., Mehl, M., Javed, T., Ahmed, A., et al., "Compositional effects on the ignition of FACE gasoline fuels," Combust Flame 169, 171-193, 2016: doi:10.1016/i. combustflame.2016.04.010

16. Nadkarni, R., "Guide to ASTM test methods for the analysis of petroleum products and lubricants," (West Conshohocken, ASTM International, 2007)

17. McBride, B.J., Zehe, M.J., Gordon, S., "NASA Glenn coefficients for calculating thermodynamic properties of individual species," (John H. Glenn Research Center at Lewis Field, National Aeronautics and Space Administration, 2002).

18. GT-Suite ${ }^{\mathrm{TM}}$ Version 7.5.0, Gamma Technologies, 2016

19. Woshini, G., "A Universally Applicable Equation for the Instantaneous Heat Transfer Coefficient in the Internal Combustion Engine," SAE Technical Paper 670931, 1967, doi: $\underline{\text { 10.4271/670931. }}$.

20. National Institute of Standards and Technology, "NIST Chemistry webbook, NIST standard reference database," http://webbook.nist.gov/ chemistry, accessed 2016.

21. Lemmon, E., McLinden, M., Huber, M., REFPROP: Reference fluid thermodynamic and transport properties (Version 9.0), Computer Software, NIST standard reference database, Boulder, CO, 2013.

22. Ahmed, A., Goteng, G., Shankar, V.S.B., Al-Qurashi, K., et al., "A computational methodology for formulating gasoline surrogate fuels with accurate physical and chemical kinetic properties," Fuel 143:290300, 2015, doi: 10.1016/j.fuel.2014.11.022.

23. Maricq, M., Podsiadlik, D., Brehob, D., and Haghgooie, M., "Particulate Emissions from a Direct-Injection Spark-Ignition (DISI) Engine," SAE Technical Paper 1999-01-1530, 1999, doi: 10.4271/1999-01-1530.

\section{CONTACT}

Dr. S. Mani Sarathy

mani.sarathy@kaust.edu.sa

\section{ACKNOWLEDGMENTS}

The authors wish to thank Mr. Adrian Ichim from CCRC engine lab for help in performing the engine experiments. The research reported in this publication was supported by funding from King Abdullah University of Science and Technology (KAUST) and Saudi Aramco under FUELCOM program. 


\section{DEFINITIONS/ABBREVIATIONS}

DISI - Direct injection spark ignition

IMEP - Indicated mean effective pressure

NOx - Oxides of Nitrogen

HC - Various hydrocarbons

CAD - Crank angle Degree

FACE - Fuels for advanced combustion engines

CA - Crank angle

aTDC - after Top dead center

TDC - Top dead center

MBT - Maximum brake torque

AKI - Anti knock index $(\mathrm{RON}+\mathrm{MON}) / 2$

S - Sensitivity (RON-MON)

OI - Octane Index

All rights reserved. No part of this publication may be reproduced, stored in a retrieval system, or transmitted, in any form or by any means, electronic, mechanical, photocopying, recording, or otherwise, without the prior written permission of SAE International.

Positions and opinions advanced in this paper are those of the author(s) and not necessarily those of SAE International. The author is solely responsible for the content of the paper. 